Revista Iberoamericana, Vol. LXIX, Núm. 202, Enero-Marzo 2003, 229-247

\title{
TRAZANDO LÍNEAS PUNTEADAS: EL TEATRO EN BUENOS AIRES A PARTIR DE LOS NOVENTA
}

\author{
POR \\ María Silvina Persino \\ Trinity College-Hartford
}

Tras la iniciativa de Teatro Abierto (1981), y recuperada la democracia, a mediados de los ochenta la producción teatral en Buenos Aires era desbordante. ${ }^{1}$ Se salió a la calle a celebrar la libertad, junto con las expectativas colectivas de que un estado de derecho traería consigo el advenimiento de la justicia; fue uno de esos momentos en que la correspondencia entre contexto político-social y teatro parecía evidente. La participación de grupos como el catalán La Fura del Baus o el peruano Yuyachkani en el Festival Internacional de Teatro en Córdoba en 1984, junto con la visita de Eugenio Barba, el padre del teatro antropológico, en 1987, resultaron experiencias que marcaron fuertemente el desarrollo teatral argentino en esa década. La presentación en espacios no convencionales, el trabajo grupal, la inclusión de técnicas del clown o de acrobacia, el manejo de un humor corrosivo, un público mayoritariamente joven, fueron algunos de los rasgos más salientes de un fenómeno de gran fuerza que se produjo en Argentina hacia mediados de los ochenta. $^{2}$ Se trataba, asimismo, de una generación de "teatristas" cuyo trabajo se basaba en una dramaturgia de actor y/o director; es decir que en la mayor parte de los casos la obra se creaba sobre el escenario, en los ensayos, a veces a partir de un bosquejo temático general. $^{3}$

La década del noventa ha sido testigo del surgimiento de muchos nuevos dramaturgos, quienes actualmente tienen entre treinta y cuarenta y cinco años. En este sentido, la crítica ha hablado de una "vuelta al autor" (vs. la marginación del texto en gran parte del teatro

\footnotetext{
${ }^{1}$ Enfoco el trabajo en la producción teatral de Buenos Aires porque mi acceso a información (tanto documental como vivencial) sobre el teatro que se hace en el resto del país es limitado. No se trata de un gesto sinecdóquico (pretender que este es el teatro que representa a toda Argentina) ni metonímico (suponer que el teatro hecho en las provincias es análogo al hecho en Buenos Aires). ${ }^{2}$ Con una heterogénea filiación estética, los grupos más reconocidos de los ochenta serían: Gambas al Ajillo, El Clú del Claun, Los Melli, La Organización Negra (algunos integrantes formaron De la Guarda*), Los Macocos *, Teatro Sanitario de Operaciones *; en lo que podría clasificarse como teatro callejero: La Runfla* y Los Calandracas*, Agrupasion [sic] Humorística La Tristeza, Escena Subterránea* con sus actuaciones en el transporte subterráneo, y el grupo de vecinos Catalinas Sur* (* indica que siguen existiendo en la actualidad). A pesar de la desaparición de la mayoría de los grupos de teatro callejero de los ochenta, entre el 22 y el 25 de noviembre de 2001, al cumplirse los diez años del grupo La Runfla, se celebró en Buenos Aires el Festival de Teatro Callejero.

${ }^{3}$ Sobre este tema, véase Dubatti (“El nuevo ...” 448-50).
} 
de los ochenta) y de un “canon de la multiplicidad” para describir este período sumamente fértil de la dramaturgia nacional, que se viene desarrollando hasta hoy, y que se caracteriza por las diferencias más que por una estética común (Dubatti, “El canon ...”). Si bien es cierto que en este panorama hay un predominio del teatro de autor, interesa poner de relieve factores que fisuran esta hegemonía y enriquecen aún más el conjunto. Por un lado, como se verá en la última sección de este trabajo, vemos la existencia de una tendencia continuadora de la experiencia de los ochenta, que busca un teatro generado desde dentro de la situación escénica, desligado del texto escrito. Por otro, la frecuencia de la figura del “teatrista” es una marca del teatro actual y relativiza la oposición binaria entre dramaturgia de autor y dramaturgia de actor y/o director (a veces encarnados por una misma persona), al mismo tiempo que nos obliga, más que nunca, a mirar el fenómeno dramático como una experiencia integral y necesariamente colectiva, donde se conciertan numerosos lenguajes. En efecto, muchos de los escritores de teatro de esta nueva camada están ligados a él desde el escenario como actores o directores, como es el caso de Daniel Veronese, cuya producción se estudiará en este artículo. Estos “teatristas” prefieren muchas veces ser los responsables de la puesta de sus propias obras, con lo que, innegablemente, la escritura se continúa en los ensayos. Asimismo, se producen coyunturas en las que los dramaturgos, si bien no actúan como directores, realizan su escritura interactivamente con actores y directores; es decir que el escritor acompaña un proceso de búsqueda creativa en el escenario, tomando notas e ideas, para luego ir plasmando este material en una obra dramática. Por ejemplo, Patricia Zangaro, autora de una de las obras analizadas aquí, ha estado involucrada recientemente en una creación de este tipo con el Grupo del Teatro Payró.

En lo que hace a la enorme variedad de poéticas, el teatro de esta década produce obras que van desde una estética cercana a la realista moderna, a veces portadora de una crítica social, hasta un teatro fundado en procedimientos y posturas ideológicas de tono posmoderno. ${ }^{4}$ Dentro de la diversidad de la producción teatral de este período, esta última tendencia, que suele desentenderse del contexto social y político como referente fundamental, y que está signada por la fragmentación, la presentación de personajes sin verosimilitud realista y los sentidos múltiples, es la que ha sido colocada en el lugar más visible y ha sido objeto de mayor atención por parte de la crítica periodística especializada y de los curadores de festivales internacionales que vienen a Buenos Aires en busca de obras (Aisemberg). Los escritores más reconocidos dentro de esta estética son seguramente Rafael Spregelburd, Alejandro Tantanián y Javier Daulte, así como parte de la producción de Daniel Veronese.

Más allá de las opciones ideológicas o de la respuesta más o menos clara al contexto político-social, se podría decir que el teatro argentino de hoy —a excepción del teatro “comercial” que nunca deja de serlo_ - es todo él un teatro de resistencia, por el sólo hecho de sobrevivir en un país castigado cada día más por la recesión económica y las "políticas de ajuste”. En Buenos Aires, la oferta teatral en un fin de semana de la temporada de

\footnotetext{
${ }^{4}$ Importa destacar una figura clave, el dramaturgo Mauricio Kartún, por cuyos talleres ha pasado la mayoría de los escritores de esta nueva camada, sin que ello les haya dado un sello de uniformidad, sino que, por el contrario, han desarrollado estéticas individuales muy diversas.
} 
invierno ronda los cien espectáculos (sin incluir los infantiles ni los “café concert”), por lo que se diría que el crecimiento teatral, fuerte apuesta por la imaginación, va a contramano de la crisis generalizada. Jorge Dubatti afirma que si bien hay un proceso de pauperización en el teatro argentino de los últimos años (reducción de presupuestos del gobierno; caída del número de espectadores), no significa esto un empobrecimiento cultural ni una merma en el caudal creativo puesto en escena, sino que ha provocado ciertos reacomodamientos que, incluso, tienen algunas consecuencias positivas ("El teatro frágil...”). En efecto, la vitalidad del teatro en Buenos Aires, fenómeno que algunos juzgan inexplicable - y en parte lo es-, pone en evidencia nuevas formas de producción que conviven con otras ya existentes. Antes que nada, la gestión de grupos independientes asociados en cooperativas es una realidad que ya predominaba en el teatro de los años del Proceso, y que hoy sigue produciendo muchas obras en el circuito teatral porteño. En estos casos, se suelen elegir obras de autores nacionales, muchas veces pertenecientes a la nueva camada, que son puestas en escena tras prolongados períodos de ensayos nocturnos (cuando los actores han cumplido con obligaciones más urgentes), y culminan en la búsqueda de una sala pequeña para una o dos funciones semanales. Si la propuesta es valiosa, el espectáculo permanece en cartel por unos meses, fenomeno al que, en mi opinión, coadyuvan dos factores: el bajo costo de las entradas y la atracción asombrosa que el teatro sigue despertando en los jóvenes porteños, sobre todo en los estudiantes universitarios. ${ }^{5}$ Este sistema se sostiene fundamentalmente por la pasión que lo provoca y, además, por el hecho de que el interés en común es de peso (y no de pesos): hacer conocer un trabajo creativo y, en lo posible, no perder dinero.

De los teatros oficiales que forman el Complejo Teatral Buenos Aires, el Centro Cultural Ricardo Rojas es el que ha mostrado una línea de política cultural más coherente; ha sido y sigue siendo un lugar en donde se les da cabida a proyectos experimentales de nuevos teatristas, si bien es cierto que la lista de espera es larga para los aspirantes a ser “oficializados”. Como modalidad de producción relativamente nueva, también se debe mencionar las gestiones de co-producción del Teatro General San Martín, que así brinda apoyo financiero parcial a producciones pequeñas de grupos independientes, seleccionadas por concurso cada año y presentadas, por lo general, en teatros del circuito off. ${ }^{6}$ Asimismo, hay una tendencia a la agrupación de autores y directores para la oferta teatral, que se viene repitiendo en los últimos años y que parece facilitar la producción de espectáculos (como ejemplos de los últimos meses: el "Proyecto Puentes”, “5 x 5”, el ciclo “Teatro de Autores” y "9 (Nueve)").

En 1997 se produjo la primera edición del Festival Internacional de Teatro y Danza de Buenos Aires, que se repitió exitosamente en 1999 y en 2001, con fondos del Gobierno

\footnotetext{
${ }^{5}$ La entrada a este tipo de espectáculo cuesta entre \$5 y \$15 (y a veces incluye un plato de tallarines o un vaso de vodka). En muchos casos, se anuncia "entrada libre” y, concluido el espectáculo, alguien del grupo pasa el sombrero para que los espectadores contribuyan a discreción ("teatro de la gorra”).

${ }^{6}$ Paradójicamente, la Secretaría de Cultura que solventa estas gestiones, en los últimos años paga con atrasos significativos los sueldos de los trabajadores en las salas oficiales (actores, directores, escenógrafos, iluminadores, etc.).
} 
de la Ciudad y de empresas auspiciantes. Este es un evento revitalizador y estimulante, que consigue atraer a algunos espectadores "vírgenes" al teatro, y renueva el interés en la producción en el campo teatral en general. En un sentido si se quiere inverso, la circulación y la producción del teatro argentino se ven estimuladas por el interés suscitado en los curadores de festivales internacionales, quienes llegan a Buenos Aires en busca de obras para incorporar a sus eventos. Así, los espectáculos argentinos se conocen en otras partes del mundo, particularmente Europa, donde son recibidos con entusiasmo y, por añadidura, se generan a veces conexiones que más tarde desembocan en una co-producción, en la que entidades extranjeras aportan fondos para una nueva obra que, antes o después, se presentará en ese país.

Por último, es importante mencionar que en 1997 se creó la Ley Nacional del Teatro y, a través de ella, el Instituto Nacional del Teatro. Desde 1997, el INT cuenta con un presupuesto de once millones de pesos (once millones de dólares) anuales destinados a subsidios (ganados por concurso) para grupos de teatro independiente y salas en todo el país. ${ }^{7}$ Con pesar, hay que decir que en el momento de elaboración de este artículo, este sistema está al borde del abismo, si no ya en el fondo. Luego de que a comienzos de octubre de 2001 se hubiera recortado en un 85\% el presupuesto de la Secretaría de Cultura para el último trimestre del año, a fin de ese mismo mes, una "partida de emergencia” no parece ser suficiente siquiera para pagar los sueldos en lo que resta del año. Posiblemente esto se traduzca en deudas que se descontarán del presupuesto para el 2002, ya de por sí puesto en duda.

Mi trabajo se enfocará en algunas obras concebidas —escritas y/o puestas en escena- a partir de 1990, representativas de ciertas tendencias que considero especialmente significativas dentro de la producción teatral variadísima y fértil de ese período. Es necesario antes establecer unas pocas y breves advertencias metodológicas: a) Se usarán indistintamente las expresiones "texto dramático" o "texto escrito" para referirse a la escritura del dramaturgo, y “texto espectacular” o “texto teatral” para aludir a la puesta en escena, con o sin un texto escrito anterior o posterior. Considero que ambos niveles del hecho teatral guardan entre sí una relación de "recíproca autonomía” o “relativa independencia” (De Marinis, “Repensar ...”) de manera que pueden ser objeto de estudio separadamente o en conjunción. b) Mi acercamiento a las obras variará no sólo en función de optimizar mi interpretación de cada una, sino también de acuerdo con mi modo de acceso al hecho teatral en cada caso. Así, en cuanto a Por un reino, de Patricia Zangaro, el análisis se basa en el texto dramático, reconociendo en él lo que se ha llamado su “teatralidad virtual” (dimensión potencial de representación presente en el texto escrito, Villegas 32, 122), junto con fotos, programa de mano y textos - periodísticos y académicos - que documentan la puesta en escena. La obra de Daniel Veronese, Cámara Gesell, ha sido recogida de fuentes similares, sumadas a la grabación de video del espectáculo. En cambio, en el caso de Cercano Oriente, obra de la cual no existe texto

${ }^{7}$ Para una información detallada del funcionamiento del sistema de subsidios del INET, modificado en el año 2001, véase Rubens Correa . Además, PROARTE (Instituto Porteño de Teatro), creado en 1999 con fondos del gobierno de la Ciudad Autónoma de Buenos Aires, entrega subsidios a grupos y salas exclusivamente de esa ciudad. 
escrito, se ha presenciado la puesta en escena en Buenos Aires en julio de 2001, y se ha contado además con una grabación de video. En todos los casos, comunicaciones personales con teatristas involucrados han provisto datos significativos para el análisis. c) Al hablarse aquí de "espectador”, se estará pensando en un espectador hipotético, que no coincide con el "espectador modelo" (llamado más tarde "implícito”), producto de un acercamiento experimental y científico, como intentó hacer la semiología teatral en los ochenta, con resultados, en mi opinión, poco convincentes. ${ }^{8}$

LOS CUERPOS DE LA MISERIA, LA MISERIA DE LOS CUERPOS

El teatro de Patricia Zangaro, reunido en un volumen con el título de Teatro y margen, tiene como personajes a actores sociales excluidos. Tomado en su totalidad, pone en evidencia una multiplicidad de fisonomías que la marginación y la opresión puede asumir. Se representan situaciones ubicadas en diferentes momentos históricos de un siempre mismo escenario, que la mayoría de las veces es Argentina, utilizando un lenguaje expresivo que no se repite de obra en obra, y que en muchos casos abreva en códigos estéticos de la tradición hispanoamericana, que encuentran en su escritura modos sorprendentes de renacer: el grotesco, el sainete, el esperpento, el autosacramental, lo gauchesco. ${ }^{9}$

En Por un reino, ${ }^{10}$ se pone en escena la miseria de una familia de mendigos cuyo patriarca, Tatita, mutila o deforma sistemáticamente a cada miembro de la familia al nacer, del mismo modo que su propio padre hiciera con él. Deformidad física usada como acicate de la caridad que les da de comer. Sin embargo, también como ellos, en los márgenes, vive Antonio el Rapiña, un delincuente violento que se sirve de los habitantes de la ciudad como presas de sus ataques. Es decir que para el Rapiña el miedo actúa como la lástima para la familia de Tatita. El encuentro de la Pochi, nuera de Tatita, embarazada y tuerta, con el bandido, provoca la curiosidad y el resentimiento en la mujer, al ser rechazada sexualmente. Vuelta a su pocilga, Pochi trae el dinero que el Rapiña le ha regalado y esto provoca la ira del jefe de familia que siente que, desde hace un tiempo, Antonio le roba "su reino", ya que la gente de la ciudad huye de los mendigos, presa del terror infundido por el

\footnotetext{
${ }^{8}$ Se debe señalar que la semiótica del teatro, durante los años ochenta, privilegió absolutamente el texto espectacular como objeto de estudio para luego restringirlo incluso más y enfocarse en la comunicación teatral (circuito actor-espectador). Ya en los noventa, se integra el texto dramático en el hecho teatral, como objeto de estudio.

${ }^{9}$ Las preocupaciones sociales y políticas de Zangaro se articulan además en sus declaraciones a la prensa, así como en su participación activa y fundante en el ciclo “Teatroxlaidentidad”. Fue ella, junto con el director Daniel Fanego y la iniciativa de las Abuelas de Plaza de Mayo, quienes en mayo de 2000, montaron "A propósito de la duda", con dramaturgia de Zangaro, que sirvió de germen, algunos meses después, para un ciclo de teatro cuyo tema central era el robo de identidad sufrido por hijos de desaparecidos. No se trataba de una simple denuncia, sino de un teatro que buscaba generar la duda y llevar a la verdad a los quinientos jóvenes que todavía hoy, se calcula, viven sin saberlo con una identidad cambiada. En octubre de 2001 se vuelve a convocar el concurso dramático para seleccionar nuevas obras que formarán parte, en 2002, de una segunda edición del ciclo.

${ }^{10}$ Estrenada en el Teatro de la Campana en 1993, con dirección de Graciela Spinelli.
} 
delincuente. Es así como el miedo ha tomado el lugar de la lástima, y la prole de Tatita ha sido desplazada y condenada a la hambruna. El viejo se propone apresar a Antonio y vengarse de él, y le dice a su prole: “¡Yo voy a llevarlos hasta las puertas de la ciudad que será nuestra! Mis armas son nuestras llagas, muñones, pústulas y bocas mordidas por la lepra” (Zangaro 71-2). Una vez atrapado, lleva a Antonio a su tapera, para esperar la salida del sol y luego castrarlo; Tatita sigue con su táctica de dominio a través de la mutilación, a la vez que priva al Rapiña de los placeres carnales que le han dado fama en la región. ${ }^{11}$ Sin embargo, los planes del patriarca no resultarán como estaban planeados, ya que la Pochi se abalanza sobre el Rapiña en busca del deseo que se le había negado. Revancha erótica sobre el hombre atado e inmovilizado. Astutamente, el Rapiña gana su libertad proponiéndole a la Pochi salvar al hijo que lleva en el vientre de la "marca" que al nacer le espera a manos del abuelo. La obra termina con el Rapiña matando a Tatita y, por error, hiriendo a la Pochi quien muere unos instantes después, habiendo dado a luz a su hijo. Antonio el Rapiña cumplirá con su promesa: el hijo de la Pochi no conocerá la lástima sino que ganará “el reino” junto a él, a través de la violencia. “Él hará temblar la ciudad”, dice Antonio (84). Entre tanto, Fratacho (hijo de Tatita y marido de la Pochi) va hacia la ciudad con su prole de "monstruitos", casi repitiendo las consignas de su padre al principio de la obra. Aunque el Rapiña, ahora con su nuevo heredero, seguirá asolando a la ciudad, el sucesor de Tatita arenga a sus hijos: “ ¡A la ciudad, mis quebrados, porque por fin volvieron los tiempos de la caridad!” (82).

¿Puede ser interpretada la obra como la representación expresionista de un futuro más que como una instantánea del presente? Si ésta no es la realidad que esperaba a la salida del teatro en 1993, en todo caso se avecinaba rápidamente día tras día y así, en 2001 y 2002, con los recortes, planes de ajuste y el desempleo en niveles sin precedentes en Argentina, la obra de Zangaro resuena más dolorosamente aún que en el momento en que fue escrita. ${ }^{12}$ Aunque, a diferencia de las otras obras de Zangaro, en Por un reino no se especifica un espacio ni un tiempo para la acción, en ella se pinta un entorno reconocible, y no sólo para los pobladores de Buenos Aires, como lo testimonia su puesta en escena por el grupo Mayombe en Belo Horizonte, Brasil (1999). Los cambios que los brasileños necesitaron hacer fueron en el nivel lingüístico (la traducción al portugués), ya que en cuanto a la contextualización, en el país vecino se vive la misma marginación y opresión de grandes sectores de la población. En Belo Horizonte, como en Buenos Aires, los ciudadanos intentan descartar la miseria, junto con la basura, fuera de los límites de la ciudad. Así describe el fenómeno Wal Souza, quien diseñó la iluminación para la puesta en escena

\footnotetext{
${ }^{11}$ Sobre las mutilaciones y deformaciones corporales en la dramaturgia argentina, véase Trastoy y Zayas de Lima, 73-5.

${ }^{12}$ Este mensaje situado entre la advertencia/amenaza y el llamado a la acción en Por un reino, evoca la obra de Egon Wolff, Los invasores (1964). Lo interesante es que en la obra del chileno, en la cual los harapientos toman posesión de la casa de una familia rica, la oscilación entre realidad o prefiguración de un futuro inevitable está tematizada en la obra. Al final, Meyer, su protagonista, despierta y comprende que todo lo que él (y los espectadores) ha(n) experimentado ha sido una pesadilla. Sin embargo, un cristal que se quiebra anuncia el recomienzo de la acción que, esta vez, no es otra cosa que la realidad. El futuro estaba demasiado cerca del presente, lo onírico demasiado cerca de la realidad.
} 
brasileña: "Essa guerra por espaços não está tão longe do nariz, dos ouvidos, da boca, do corpo mas está longe das vistas da cidade, que abaixa os olhos para não ver o que acontece. Longe das vistas dos cidadãos que fingem não ver a ferida crescendo, nem sentir o seu mau cheiro, enquanto as disputas (menores) avançam pelas ruas, com muletas e facas” (29). ${ }^{13}$ En la realización escénica brasileña, se aplicaba un antídoto contra la indiferencia: al fondo del escenario se proyectaba un video "casero" que mostraba alternadamente imágenes de la miseria y de la opulencia, con tomas reales de la zona de Belo Horizonte. No obstante, opulencia y miseria tienden a mezclarse cada vez más en la multitud de la ciudad. Así, en la Argentina de los años sesenta, se hablaba de "bolsones de pobreza”, pero hoy en día, en los noventa, la villa 31 de Retiro, en la Capital Federal, por ejemplo, forma parte de una zona céntrica de la ciudad, "emerge en el espacio urbano para incomodarlo, y señalar los contrastes de la supuesta modernización y sus avances” (Szulik 195-7). Cada día es mayor el número de expulsados del sistema que piden dinero en la vía pública, intentando provocar la lástima de una población más y más inmunizada contra ella. Además, el empobrecimiento creciente — la prole de Tatita cada vez más numerosa— ha traído consigo una criminalización de la pobreza, representada en la obra por Antonio el Rapiña que aconseja: “¡No extiendas la mano sino para empuñar el arma!” (60). Y con la creciente inseguridad de las calles de Buenos Aires viene el miedo, que entonces predomina, y no hace sino empujar a los ciudadanos a una suerte de implosión emocional, que los aísla del entorno social que se resquebraja a velocidad alarmante. ${ }^{14}$ No hay lugar para la mirada y menos aún para la compasión. Así, la amenaza expresada por Zangaro no es solamente la invasión de la ciudad por ejércitos de mendigos deformes implorando ayuda, sino la incorporación creciente en el mundo del crimen de los individuos marginados, tal como la escena final sugiere; en fin, la definitiva descomposición social.

Algunos resultados preliminares del Censo Nacional realizado en Argentina en noviembre de 2001 (diez años después del anterior) pueden arrojar alguna luz sobre esta lectura de Por un reino. La población de la capital parece haberse reducido en un 10\%, y me atrevo a especular sobre la identidad y el destino de los que se fueron. Una proporción pequeña de esta ausencia se explica por los siguientes factores: el descenso del número de hijos en las mujeres urbanas en general, un número limitado de pobladores que eligieron la salida del país y, por último, cierto margen de error en un censo que se caracterizó por la improvisación. Fuera de esto, una interpretación tentativa nos conduciría al movimiento de doble vía sugerido por la obra de Zangaro. Por un lado, la ciudad se vacía al expulsar a sus habitantes más allá de sus márgenes y, en menor medida, a los barrios más pobres dentro de la ciudad (dos de estos distritos fueron los únicos en mostrar un aumento de población). Por otro, hay una tendencia mundial de las clases acomodadas a trasladar su residencia fuera de las ciudades, que en Argentina ha cobrado formas extremas: los

13 “Esa guerra por espacios no está tan lejos de la nariz, los oídos, la boca, el cuerpo pero está lejos del horizonte de la ciudad, que baja los ojos para no ver lo que sucede. Lejos del horizonte de los ciudadanos que fingen no ver la herida creciendo, ni sentir su mal olor, mientras disputas (menores) avanzan por las calles, con muletas y cuchillos” (mi traducción).

${ }^{14}$ Sufren "el bloqueo de un tipo de sensibilidad que frente al horror hubiera respondido de una manera dramatizadora y explosiva; así el horror y el dolor paulatinamente no constituirán más un acontecimiento" (Bergero 63). 
“barrios cerrados” en ciertas áreas fuera de la Capital, donde los ciudadanos de clases privilegiadas buscan refugio contra la inseguridad creciente de Buenos Aires. De manera que la miseria en un caso, y el miedo en otro, empujan a estos dos grupos ubicados en los extremos del sistema socio-económico (cada vez más polarizado) fuera de la ciudad. Unos expulsados y otros protegidos (¿o encerrados?) en sus barrios (¿`o cárceles?) de lujo. Paradójicamente, todos comparten la periferia de la ciudad, aunque en zonas muy diferenciadas, y también comparten la ciudad, ya que unos y otros vuelven a ella durante el día: los afortunados para trabajar y los desafortunados para buscar trabajo inútilmente, mendigar y hasta robar.

El desenlace de Por un reino propone preguntas complejas. ¿Debemos ver en el hijo recién nacido de la Pochi la imagen del que fue rescatado? Sin duda fue salvado de ser objeto de la crueldad de la mutilación, pero sólo a costa de ejercerla en cuanto tenga edad para hacerlo. No olvidemos que ese será su destino al crecer junto a Antonio y que todo parece anunciar que, de no haber sido así, aunque Tatita ha muerto, el nuevo rey, Fratacho, lo habría “marcado” sin piedad. ¿Ejercer la violencia es la única forma de no ser presa de un sistema que, como Tatita a su prole, desfigura y maltrata desde el momento de nacer? En todo caso, estamos ante la escenificación de una brutalidad insoslayable que da a elegir entre ocupar el lugar de la víctima o del verdugo. Se podría ver en la escena final de los “monstruitos” siguiendo a su padre Fratacho, y en ese otro hijo "rescatado" por el Rapiña, las dos opciones ofrecidas al individuo oprimido hoy por las condiciones de vida miserable. Así y todo, la sola voluntad de hacer reaccionar al espectador de clase media que asiste al teatro, implica un gesto de cierta esperanza; en efecto, significa creer en la posibilidad de detener ese futuro inminente (más bien apenas la intensificación de un presente) por medio de la concientización social, y confiar en el teatro como medio movilizador. Como ha dicho Zangaro, ella no propone soluciones, solamente denuncia el problema.

Si Por un reino muestra el proceso de “desciudadanización” que grandes sectores de la población enfrentan en los últimos años, como consecuencia de la exclusión socioeconómica (Grüner 111), es importante enfatizar que toda la obra teatral de Zangaro está insertada en la serie social, y pone en escena, a través de estéticas y procedimientos renovadores, una denuncia a voces. No podría ser de otra manera en la creación de alguien que ha declarado:

Y si, como reflexiona Jameson, esta glorificación de un presente ahistórico y acrítico, esta
"naturalización” de lo dado que supone el pensamiento posmoderno, es la expresión
cultural del capitalismo tardío, las luchas por la identidad, por la reinscripción de la
historia, por la recuperación de un lugar crítico y de transformación para el sujeto,
constituyen, hoy por hoy, la forma más radical de rebelión y resistencia” (Citado en la
convocatoria para el ciclo “Teatroxlaidentidad” del 2002, Zangaro “Rebeldías ...”).

El DESARROLLO DEL CRIMEN, EL ASESINATO DEL DESARROLLO

Se ha dicho que la obra de Daniel Veronese encarna la poética de la diversidad que caracteriza al panorama teatral porteño de los últimos quince años (Dubatti, “La dramaturgia 
...”397). En efecto, su escritura abarca un rango que va desde una estética moderna heredera de la obra de Griselda Gambaro y Eduardo Pavlovsky, hasta las exploraciones de un teatro fragmentario, en parte inspirado en sus experiencias con títeres y objetos, donde el concepto de comunicación o de personajes como entidades sicológicas aparecen completamente desbaratados, y que la crítica ha caracterizado como "teatro de intertexto posmoderno" (Pellettieri). ${ }^{15} \mathrm{Y}$ no se trata de un cambio progresivo que obedece a la cronología de la creación de Veronese sino que me inclino por ver su obra como la coexistencia de distintas estéticas cristalizadas con diverso énfasis en cada una de las piezas dramáticas.

Cuerpo de prueba (1997), el primer volumen publicado por Veronese, al cual pertenece la pieza seleccionada para el análisis, reúne tanto textos dramáticos que podríamos llamar obras para actores, como obras creadas para que El Periférico de Objetos - grupo del que Veronese es uno de sus fundadores y directores - las pusiera en escena con actores, marionetas y objetos. Es necesario detenernos un momento sobre este grupo y su relación con Daniel Veronese, quien durante los ochenta se formó y trabajó con el prestigioso Grupo de Titiriteros del Teatro Municipal San Martín, bajo la dirección de Ariel Bufano y Adelaida Mangani. Esta experiencia es esencial en el lenguaje del grupo que inician él y otros cuatro titiriteros del San Martín, en 1989, y con el que ponen en escena un teatro de objetos (predominan las muñecas y marionetas de tamaño humano) y actores simultáneamente. ${ }^{16}$ Si bien algunas de las creaciones de El Periférico de Objetos son adaptaciones de obras de otros autores (por ejemplo la primera, Ubú Rey de Alfred Jarry, en 1990), otras son escritas por el mismo Veronese, cuya labor dentro del grupo fue cambiando y alejándose del lugar de manipulador de objetos para gravitar más en el rol de autor y director. ${ }^{17}$ Aunque a partir de Circonegro (1996), El Periférico comienza a incorporar textos dichos por actores en escena, en general sus obras presentan un diálogo breve y esporádico, cuando existe, y predomina un tipo de texto de naturaleza fronteriza entre lo narrativo y lo descriptivo, a menudo expresado por una voz fuera de escena. De

\footnotetext{
${ }^{15}$ Pellettieri habla de "teatro de intertexto posmoderno", en la medida en que integra algunos elementos de la semántica y procedimientos del posmodernismo. Según él, en el panorama del teatro argentino actual "no hay elementos suficientes para calificar a tal actor, director o autor de posmoderno” (153).

${ }^{16}$ Se ve en las producciones de El Periférico cierta impronta del teatro de Tadeusz Kantor. En efecto, las visitas del director polaco a Argentina con Wielopole, Wielopole (1984) y Que revienten los artistas (1987) tuvieron fuerte influencia en la escena argentina. Kantor, en El teatro de la muerte, habla sobre su introducción del uso de maniquíes en su teatro (Kobialka 111-2). No obstante, los muñecos de tamaño natural utilizados por El Periférico (en Zooedipous, por ejemplo), se apartan de los kantorianos en tanto no son rostros anónimos sino verdaderos “dobles” de los actores (sus caras están hechas a su imagen y semejanza) y, además, cobran vida en manos de los titiriteros.

${ }^{17}$ El Periférico de Objetos ha estrenado ocho espectáculos desde el primero en 1990 (el último, Monteverdi, método bélico, en 2000), y desde mediados de 2001, se encuentra preparando uno nuevo, cuyo tema girará en torno al suicidio. En todos estos años, viajaron por el mundo participando en diversos festivales donde ganaron la admiración de un público internacional. Mientras tanto, sus obras son seguidas en Buenos Aires por un público interesado en este tipo de puestas que no se adaptan, por supuesto, al gusto de la mayoría. Más aún, sus obras pueden producir verdadera repulsión en el espectador al poner en escena una y otra vez lo obsceno.
} 
este modo, se introduce una modalidad discursiva que, no sólo pone en cuestión el origen del texto (¿personaje? ¿dramaturgo ficticio?) sino también el destinatario. ${ }^{18}$ El espectador está escuchando un texto que los personajes en escena no escuchan, situación ajena a la teatralidad tradicional, salvo en la convención del “aparte”. Por otra parte, esta filtración de la narración en la representación teatral (dos modalidades tan opuestas para Aristóteles) se repite en la dramaturgia de Veronese no sólo en los textos escritos para el Periférico, sino también en el segundo volumen de teatro, La deriva (2000). En él no incluye -al menos explícitamente- piezas para su puesta en escena con el grupo, sino que parece tratarse de obras para actores, aunque también incluye materiales diversos, ya que junto con textos, con personajes y diálogos, se publica uno de índole narrativa (Eclipse de gato) y un texto híbrido, en donde los personajes tienen parlamentos que son, en realidad, descripciones de las acciones del otro personaje (XYZ).

Dentro de la diversidad poética de la obra de Veronese como dramaturgo, llama la atención la recurrencia de ciertas temáticas que son como líneas subterráneas que atraviesan gran parte de su producción, por ejemplo, la presentación de los lazos familiares como un mecanismo tortuoso. Concuerdo con Jean Graham-Jones cuando afirma que, en el teatro occidental contemporáneo, la familia es frecuentemente puesta en escena, como representación sinecdóquica de la sociedad en general (28). En este sentido, Veronese opera una disección de la mecánica familiar, que integra tanto en sus textos para actores como en los escritos para El Periférico (Cámara Gesell), a la vez que no está ausente de los espectáculos creados por el grupo que él co-dirige (Zooedipous, Máquina Hamlet).

Incluida en Cuerpo de prueba, Cámara Gesell es entonces uno de los textos escritos por Veronese para El Periférico de Objetos, estrenada en el teatro Babilonia en 1994, y codirigida por él y Emilio García Wehbi (también titiritero en la obra), cuyo eje temático es el (dis)funcionamiento familiar. El texto es dicho por una única voz fuera de escena cuya textura, sin embargo, no es homogénea. Por un lado, aunque predomina una ostentosa objetividad, el narrador tiene ciertos momentos omniscientes en los que se desliza su posición frente a los hechos. Un ejemplo sería cuando, muy al comienzo, luego del bochorno familiar que para Tomás ha sido su cumpleaños de cinco, la madre hace uso del “instinto maternal” para anticipar la reacción del hijo. El narrador introduce entonces una cláusula hipotética irreal que revela su interpretación: “adivinando la intención de Tomás le dice con tono trágico, como si ellos fuesen los despojados: 'no es bueno desear la muerte de la familia de uno"” (183 énfasis mío). Asimismo, esta voz anónima no solamente es portadora de la narración en presente, sino que también absorbe tanto los escasos discursos directos de los personajes, como la didascalia. Por ejemplo, cuando comienza, describe la disposición de los personajes en el escenario: “Tomás a un costado de la mesa. Su madre primera es quien tocaría con extender la mano derecha hacia adelante” (183); más adelante se da la siguiente indicación de puesta, para la escena de la tortura: "En esta escena, el actor que personifica a Tomás es reemplazado por un objeto, ya que debe ser víctima de algunas vejaciones y abusos por parte del personal” (189). En efecto, Tomás es el protagonista de Cámara Gesell y la única criatura de carne y hueso en la puesta de El Periférico, rodeado de personajes representados por muñecas antiguas, magistralmente manipuladas por

${ }^{18}$ Para este tema véase Trastoy (2001). 
titiriteros de expresión completamente neutra, ropa negra, gorro negro, pero sin guantes, que a veces incluso parecieran prestar sus brazos a los muñecos, como prolongaciones de los suyos. ${ }^{19}$ Titiriteros, en fin, a plena luz del día. Se establece así un contraste de tamaño entre Tomás por un lado, y los bellos muñecos y sus pocos y diminutos objetos escénicos, por otro, que junto a las "trampas" en el escenario por el que aparecen y desaparecen personajes, sugieren a un niño en su casa de muñecas. A esta construcción visual se le suma, auditivamente, el ritmo pausado y melodioso de la voz en off, y algunos armoniosos segmentos musicales, de manera que podrían producir, engañosamente, el efecto de estar escuchando un cuento infantil. ${ }^{20}$ Cruel ironía: nada más alejado del destino de Tomás. El niño-protagonista se siente maltratado por su familia, la cree ajena y huye de ella, para adoptar una nueva familia, una nueva historia. Sin embargo, va a descubrir pronto que los personajes de este segundo grupo se parecen notablemente a los de su familia primera, estableciendo una dolorosa condena a la repetición ("El parecido entre su nuevo hermano y el anterior es aterrador. Lo mismo cabe para sus padres”, 185). La escena de la huida del hogar es inmensamente sugerente en la teatralización: Tomás abandona a su primera familia, y camina dándoles la espalda pero, en verdad, lleva arrastrando tras de sí a sus parientes (muñecos sujetados por una larga correa). Huida inútil. Tomás escapa de una a otra familia sin darse cuenta de que se trata más bien de un retorno o un descenso a un infierno de círculos concéntricos. Como en otras creaciones de El Periférico, lo siniestro, en tanto aparición del mal en lo familiar y cotidiano (a la manera freudiana), está presente en Cámara Gesell.

El odio va gestándose y creciendo en el niño que terminará víctima de su propia historia. En la escena 5, "El envenenamiento”, Tomás toma el papel de verdugo y mata a su familia. En los interrogatorios policiales que le siguen, dos torturadores están presentes, personajes que "si los observamos bien, sí podrían confundirse dolorosamente con su padre segundo y su madre segunda, sin ninguna duda" (188). La asistente social que visita a Tomás en la cárcel guarda un parecido notable con Amanda, la vecina "amiguita” del padre segundo, que a su vez recordaba bastante a la vecina del primer hogar. ${ }^{21}$ Los

${ }^{19}$ El cuerpo enjuto y frágil de Laura Yusem da vida a un Tomás que resulta, de algún modo, asexuado, pero no por falta de pulsiones sexuales, sino porque su actuación no llama la atención sobre el hecho de que se trate de una mujer encarnando a un personaje masculino.

${ }^{20}$ En cuanto al resto del código sonoro en el texto espectacular, por una parte, debe destacarse la acertada selección en la musicalización de Claudio Koremblit, cuyo "collage” musical resulta fundamental en la creación de climas muy diversos. Por otra, los personajes no son mudos, ya que emiten pequeños sonidos (exclamaciones, gemidos apenas perceptibles) y mantienen largos diálogos y monólogos simulados en un lenguaje ininteligible (ausentes en el texto original de Veronese).

${ }^{21}$ El texto teatral añade escenas que de alguna manera estaban latentes, silenciosamente, en el texto dramático y que aportan nuevos elementos a la interpretación de la historia de Tomás. Por ejemplo, en el texto escrito se habla de una "tensión entre los integrantes [de la familia] por la entrada de Amanda al hogar” (187). Esta afirmación queda desarrollada en la teatralización, donde se acaba de mostrar una escena dolorosa y reveladora: Tomás se involucra en lo que parece ser su iniciación sexual con Amanda, y es sorprendido por su padre que lo quita de en medio y ocupa su lugar (inquietante cópula en escena de humano y muñeco primero, de dos muñecos después). Inmediatamente, llega la madre y, silenciosamente, presencia la escena de adulterio. 
personajes de las celdas contiguas, que verán a Tomás asesinar a la asistente social, provocan aún más su confusión, ya que se parecen a su mamá primera, papá segundo, hermano segundo.... cuando se acercan amenazadores al concluir la obra.

El título de la pieza de Veronese resulta fundamental para su interpretación. "Cámara Gesell” es el nombre del dispositivo de observación creado por el sicólogo infantil Arnold Gesell en la década de los treinta: una ventana cuyo vidrio permite la transparencia de un lado y la opacidad (una superficie que refleja como espejo), del otro. Se concibió como facilitador de la observación de los niños en el ámbito de un centro materno-infantil, por parte de estudiosos e investigadores. Justamente, Cámara Gesell no es otra cosa sino la observación del desarrollo del niño Tomás. En este sentido, la intervención de la asistente social cuando Tomás está en la cárcel resulta chocante, si la entendemos como la personificación y deformación de los sicólogos que Gesell tuvo en mente para su invención. Ahora la profesional lo interroga sobre su infancia, para averiguar las causas de su perversión y maldad. Las preguntas mecánicas, sin tiempo para la respuesta, son significativas: “¿Concebido por...? ¿Criado sin...? ¿Ignorado con....? ¿Besado a la edad de....?” (189). La grotesca distorsión consiste en que, de verdad, se trata de la paulatina observación de la de-formación de un niño a manos de su familia.

Estas reflexiones adquieren una carga adicional cuando se piensa en la extensión en el uso de la cámara Gesell —en Departamentos de Policía, por ejemplo— que desarrolló una dimensión siniestra, en potencia en el invento de Gesell, y que lo pone mucho más cerca de la vigilancia que de la mera observación. No obstante, hay aquí otra distorsión, hasta del mismo concepto de vigilancia: si en los Departamentos de Policía este dispositivo óptico se usa para observar al acusado en busca de posibles pruebas, en la obra de Veronese, en cambio, el vidrio engañoso sirve para crear testigos del sujeto de observación cometiendo el crimen mismo (el asesinato de la asistente social). En todo caso, Tomás no se ve beneficiado por la observación a la que es sometido — intención original de Gesell— y sólo se trata de asistir impasiblemente a la tortura moral y física que tuerce su destino. Si bien es cierto que el teatro puede ser considerado en sí mismo una cámara Gesell, ya que observamos impúdicamente y sin ser observados —en virtud de esa "cuarta pared” que se vuelve transparente-, esta situación se esencializa en el texto espectacular de Cámara Gesell por el espacio escénico elegido. El teatro Babilonia, ámbito ya de por sí reducido, se limitaba aún más con unas gradas contiguas al escenario donde se sentaba a los espectadores, dándoles así una cercanía fuera de lo habitual. A juzgar por los comentarios críticos de la prensa y algunas declaraciones de los directores, la obra, por su contenido y sus imágenes sumadas a la proximidad del escenario, producía una conmoción emocional, tal vez basada en parte en la yuxtaposición de la inmediatez espacial y la impunidad del observador, facilitadas por el dispositivo óptico de Gesell y reproducidas aquí por el texto espectacular de Veronese y García Wehbi.

Como se ha dicho, en esta puesta en escena — como en otras del grupo — el manejo de los títeres es abiertamente visible, ${ }^{22}$ de manera que no solo activa sino que exacerba en

\footnotetext{
${ }^{22}$ Mucho podría decirse sobre las diferentes técnicas de manipulación de títeres pero, sobre todo, de la relación muñeco-marionetista, que puede asumir maneras muy distintas. De hecho, en los espectáculos de El Periférico (que siempre ha trabajado una manipulación no oculta), tanto el tipo
} 
el espectador "el doble régimen de creencias ... [cuando] percibe las acciones teatrales en su literalidad autorreflexiva, mientras que, por otro, al mismo tiempo, la descifra selectivamente en cuanto acciones representativas, que remiten a algo diferente de sí mismas, y por lo tanto ficticias” (De Marinis, Entender ... 31). Si a ello se suma el diseño de damero pintado en el escenario del teatro Babilonia, Tomás pasa a ser una pieza de un juego siniestro, y queda en evidencia la distorsión mimética que lleva al espectador a imaginarlo a él -único ser vivo en escena - como objeto inerte manipulado en el tablero por manos ajenas, y en cambio, ver a los muñecos como seres vivos, al dejar fuera de foco y casi olvidar a los manipuladores que los animan. Así, a pesar de la presencia visible de los manipuladores en escena, de tamaño humano frente a la pequeñez de las muñecas, a pesar de que haya momentos en que incluso dos titiriteros manejan a una misma marioneta (sistema japonés Bunraku), el espectador se concentra en forma creciente y excluyente en las muñecas, seres que bailan, comen, corren, fornican, juegan, matan, se miran.

¿Cuán lejos está la historia de Tomás del entorno social, el aquí y ahora en el que se concibe Cámara Gesell? Como ha pasado con otras obras escenificadas por El Periférico de Objetos, algunos espectadores han creído ver ciertas metáforas políticas, a veces para sorpresa de los mismos creadores. Por ejemplo, El hombre de arena provocó comentarios del público y de la crítica profesional que la interpretaban en función del tema de los desaparecidos, sobre todo por el siniestro rito de enterramiento y desenterramiento (de cuerpos personificados por muñecos) que era central a la obra. Del mismo modo, la tortura padecida por Tomás en la cárcel, con instrumentos "similares a los usados por dentistas" (circunloquio para "picana eléctrica”) también arranca asociaciones dolorosas con la represión operada por los militares argentinos durante la "guerra sucia”. Incluso, la incertidumbre de Tomás respecto de su pertenencia a su primera familia podría enlazarse con la identidad falsa dada a muchos hijos de desaparecidos una vez “adoptados” por unos padres que se harían pasar por los verdaderos. Interpretaciones válidas, ancladas en el imaginario de las generaciones de teatristas y espectadores argentinos, dolorosamente castigadas por el trauma de la dictadura, que de este modo aflora en buena parte de los productos artísticos concebidos desde entonces, a veces aún sin proponérselo los creadores, al tiempo que es percibido por un público, también predispuesto a reproducir en lo que ve la huella de ese dolor histórico. No obstante, creo que la historia de Tomás quedaría reducida en su significación si se la leyera/viera exclusivamente a través de esta lente. Más bien, me inclino por pensar que en esta obra , lo mismo que en muchas otras tanto de la dramaturgia de Veronese como de la producción espectacular de El Periférico de Objetos, hay una manipulación de la identidad y una victimización que surgen sobre todo de una visión oscura del ser humano, que revela la perversión y el carácter destructivo de las relaciones interpersonales, y así articula una amarga crítica social, focalizada en la institución familiar. Los periodistas de espectáculos han hablado del personaje de Tomás como la quintaescencia de la imagen negativa del hombre de fin de siglo. Veronese, sin embargo, como uno de sus directores, reacciona ante estas afirmaciones con una postura que trasciende el nihilismo: "todo hecho teatral (toda creación artística) implica una

de muñecos como su interacción con el manipulador/actor se ha ido modificando, se diría que evolucionando hacia una mayor intervención actoral del titiritero. 
mirada positiva, de creencia en la función y el valor que cumple el teatro, al menos en el espíritu del propio artista. ... Plasmar una visión negativa en nuestro universo dramático no significa promover el pesimismo en el espectador: es una advertencia del mundo que vemos, nunca una solitaria apología de la crueldad y la tragedia” (“El periférico ...”).

\section{HACIA LA AUTONOMÍA ESCÉNICA}

Llevados por convicciones ideológicas en algunos casos, y en otros por las fuertes restricciones económicas, en los últimos tiempos se ha hecho más frecuente en Buenos Aires el fenómeno de un circuito teatral que se podría considerar "invisible”, "periferia del off”, "off del off”. Así, la casa de uno de los actores, el estudio del director, un patio, se pueden convertir en el espacio donde se produce un hecho teatral de singulares características, promocionado por "el boca a boca” y con cabida para unos pocos espectadores. En el caso de Cercano Oriente, se llega a este circuito no por una estrategia, sino al cabo de un proceso de trabajo y por una serie de circunstancias. La obra fue estrenada en 1997 en el Callejón de los Deseos, donde se pudieron solventar solamente ocho funciones, ya que había un "seguro de sala” de por medio. ${ }^{23}$ Luego se continuó en un espacio cedido por el ya mencionado Centro Cultural Ricardo Rojas, donde se empezó a generar una corriente de público estable, que superaba las veinte sillas alineadas en un ámbito poco convencional dentro del Centro. Luego de unos meses, el Rojas, circunstancialmente, decidió cerrar el espacio que había cedido al grupo. Así, sus integrantes archivaron Cercano Oriente en el rincón de las experiencias preciosas. Luego de algo más de cuatro años, en 2001, decidieron darse el gusto de presentarla de nuevo en cinco funciones gratuitas, en el estudio de uno de los actores, es decir, en una casa cualquiera de una calle cualquiera y poco iluminada del barrio de Chacarita. La respuesta favorable del público prolongó la experiencia por un tiempo más, y es en ese ámbito y en esas circunstancias que tuve la oportunidad de verla en escena. ${ }^{24}$ Aún sin proponérselo, la ausencia de un programa de mano, de una ficha técnica, incluso de un boleto (entrada, taquilla) provocaba en los espectadores de la calle Concepción Arenal, la sensación de ser testigos de un hecho casi secreto, reservado para unos pocos enterados..$^{25} \mathrm{El}$ trozo de papel arrancado de algún lado, de forma irregular y en blanco era la única constancia de que el espectador había estado allí un rato antes y por lo tanto tenía derecho, sin dinero de por medio, a ocupar un lugar en los bancos largos que albergaban a unos pocos espectadores.

\footnotetext{
23 "Seguro de sala” es un mínimo de ganancia para el teatro que, si no se cubre con el abono de las entradas debe ser pagado por la cooperativa.

${ }^{24}$ El último viernes de noviembre de 2001 fue la última función de Cercano Oriente en el estudio de Catalán, luego de haber formado parte de la oferta local en el III Festival Internacional de Danza y Teatro en Buenos Aires, en octubre de 2001. Se trata de un ejemplo de la gran flexibilidad que muestra la escena porteña en los últimos tiempos. Casi siempre por puras circunstancias, una obra puede transitar no solamente entre circuitos de teatro independiente más o menos marginales sino también en salas o eventos sostenidos parcial o totalmente por presupuestos del gobierno, es decir el teatro "oficial".

${ }^{25}$ Supe después que para las últimas funciones en el estudio se había creado un programa de mano que tenía, después de todo, la simplicidad de un volante.
} 
Se trata de un hecho teatral que se produce con lo mínimo indispensable, y que por eso mismo pone en primer plano su esencia teatral, su "ser teatro". En la obra, que dura algo menos de sesenta minutos, Luis Machín y Alejandro Catalán, dirigidos por Omar Fantini, ponen sus cuerpos y sus voces — más que sus palabras—al servicio de un juego escénico que resulta deslumbrante, aún cuando por todo equipo de iluminación haya un interruptor de luz. Respaldando esta creación, hay una convicción acerca de lo que, en la opinión de sus artífices, es una continuación de la práctica de teatro "under” o "alternativo" en los ochenta, que dio lugar a lo que ellos han llamado "producción de sentido actoral" (Catalán 17). Teatro que se quiere "huérfano", auto-generado, nacido de la nada en el escenario por virtud de la imaginación de actor y director; actores que son creadores más que intérpretes, y dominan esta nueva capacidad autónoma: "la producción de devenir escénico por una voluntad interior a la situación escénica” (15). Esta línea de creación se inscribe, por un lado, en una tradición anti-ilusionista dentro de las teorías de actuación, particularmente representada por Vsevolod Meyerhold y Tadeusz Kantor, quienes a comienzos de los sesenta, bogaban por un teatro "autónomo": “The theater that I call autonomous is the theatre that is not a reproductive mechanism, i.e., a mechanism whose aim is to present an interpretation of a piece of literature on stage, but a mechanism that has its own independent existence" (Kobialka 42). Por otro lado, se trata de una concepción que revaloriza el cuerpo del actor como centro del hecho teatral, continuadora de una tendencia iniciada y promovida por gente como Adolphe Appia, Antonin Artaud, Meyerhold, Kantor y Eugenio Barba. ${ }^{26}$ Los tres artífices de Cercano Oriente fueron, además, discípulos de Ricardo Bartís - y actores en sus obras más exitosas, como El pecado que no se puede nombrar - cuya concepción del teatro y técnica actoral han resultado sumamente innovadoras en la escena porteña de la última década. Sin embargo, parece claro que la propuesta del grupo de Cercano Oriente lleva todos estos planteos teóricos un paso más allá. Las obras de Bartís, basadas también en un teatro de intensidades y de mundos autónomos, que clausuran la noción de representación y no están originadas en un texto dramático, otorgan a la palabra, no obstante, una dimensión poética e ideológica, y producen a posteriori un texto (un “guión”) que en algunas ocasiones ha sido publicado. Sus espectáculos suelen incluir un cierto nivel metafórico alusivo a un contexto político-social, mientras que la concepción de Cercano Oriente queda expresamente desligada de todo referente extraescénico.

La ideología teatral que sustenta Cercano Oriente determinó, por supuesto, su modo de gestación: en el principio fue el juego con las cintas métricas retráctiles (de una plasticidad y una sonoridad muy peculiares) y, más tarde, irrumpió una caja de cartón que alguna vez contuvo un refrigerador; ambos elementos resultaron sugerentes y fértiles para el trabajo creador de los ensayos. Ahora bien, ¿hasta qué punto esta genealogía resulta perceptible en el producto cultural con que el espectador se confronta? Si bien es cierto que no se narra una historia, y que la palabra, escasa, aporta muy pocas claves para la interpretación, la "pulsión hermenéutica” del espectador (De Marinis, Entender ... 103) prevalece y lleva a identificar conflictos que disparan el resto de la acción, una dinámica

\footnotetext{
${ }^{26}$ Para un excelente estudio panorámico del tratamiento del cuerpo en distintas teorías teatrales, véase Trastoy y Zayas de Lima, especialmente 31-47.
} 
interpersonal (dominador y dominado), un desarrollo, una dirección, subidas y bajadas de tensión. Apenas se prende la luz, de la caja de cartón salen voces, y muy pronto nos damos cuenta de que se han abierto tres de sus cuatro aristas, de manera de producir una puerta que se abre y se cierra, vía de acceso de los personajes en las dos direcciones. A partir de ahí vemos a dos hombres que, de manera bastante precaria y sucinta, se comunican acerca de un objetivo que entre los dos intentan alcanzar, y que parece tener que ver con una sintonía: la cinta métrica se mueve y vuelve a mover en el aire y se menciona la palabra “antena”. En medio de la búsqueda "técnica" sucede lo imprevisto: uno de ellos “desaparece” dentro de la caja. A partir de allí, el objetivo escénico cambia, y ya no es lograr la imagen perfecta con la orientación de la antena, sino que el personaje visible encuentre al otro. Se escucha su voz ("Estoy disuelto") pero no se lo ve. Luego de diversos intentos de rescate, el personaje reaparece en una versión deformada de sí mismo, que agrede al que había sido su salvador. Una vez que el reaparecido recobra su forma completa, casi inmediatamente, vemos como la caja “chupa”, aspira, traga al otro personaje. Allí termina el espectáculo. ${ }^{27}$

Entre tanto, la obra parece sostenerse sobre ciertos ejes expresivos. Primero, la caja permite el manejo constante de dos espacios contiguos y antagónicos, adentro y afuera, que no sólo establecen una dinámica entre los dos personajes sino también entre ellos y los espectadores. Está en juego lo que se ve y lo que no se ve. Segundo, en parte por lo que se oculta a nuestros ojos y en parte porque todo esto ha empezado in medias res, a los espectadores nos falta información, y el permanente uso de pronombres ("lo", "la”, “ella”), lo mismo que la precisión con que se mencionan componentes técnicos inverosímiles, no solamente azuza nuestra curiosidad, sino que también produce una línea sostenida de humor, ya lanzada al comienzo de la obra, con los dos hombres compenetrados en una labor que se diría trivial (sintonizar), con un ahínco como si de ello dependiera su vida. De este modo, acciones, personajes y texto van recortando un vacío referencial que no produce, sin embargo, angustia alguna. En lo que hace al trabajo corporal de los actores, uno de los momentos más brillantes de la obra es cuando de debajo de la caja (la cara inferior ha sido quitada), se asoma "algo" que no sólo se comporta y es tratado como si fuera una mascota, sino que además lo parece. Necesitamos una operación intelectual adicional y no instantánea, para darnos cuenta de que se trata solamente de un codo flexionado que sale por debajo de la caja. Este momento se inscribe en lo que viene a ser el tercero y último de los ejes expresivos: el juego entre lo aparente y lo verdadero, entre lo que se ve y lo que es. El codo es un animalito, una gabardina en una percha se convierte ante nuestros ojos en un atacante, y la mano del actor ya no es la suya sino la del otro que lo ataca; del mismo modo, unos zapatos invertidos que simulan ser pies, pero están vacíos, asoman por el borde superior de la caja (la cara superior también se ha quitado), y se van moviendo para crear la apariencia de personajes cabeza abajo dentro de ella. Más de una vez, lo que parece moverse por sí mismo en verdad es movido (el codo/mascota, la

\footnotetext{
${ }^{27}$ En cuanto al nombre del espectáculo se podría hacer más de una especulación, y ninguna, al menos en mi opinión, resulta conducente. Posiblemente por eso, el público rebautizó a la obra "La Caja”. No debe confundírsela con La caja (ciega), espectáculo puesto en escena por el Grupo Mano de Obra Desocupada en 1998.
} 
gabardina/atacante); lo que parece movido, en realidad se mueve por sí mismo (la “aspiración” que hace desaparecer al personaje al final). Verdadera prestidigitación corporal.

Se podría postular que este juego de apariencia-realidad, y la consiguiente y repetida ilusión-desilusión perceptiva del espectador, lo mantiene todo el tiempo consciente de la artificialidad teatral, ya que produce una referencialidad que inmediatamente queda desmentida. Así, el doble régimen de credibilidad en la recepción del espectador (del que se habló en el análisis de Cámara Gesell), es aquí activado al máximo: se vuelve vertiginosamente intermitente. Sin embargo, más allá de su evidente textura fabricada, de la falta de una historia siquiera hilvanada, la obra no puede dejar de despertar asociaciones con nuestro imaginario cultural. En este sentido, Cercano Oriente podría ser una exploración de las relaciones interpersonales, de las vicisitudes del trabajo en equipo, y sobre todo, de la competencia llevada a la destrucción. Presión cotidiana que amenaza con no dar tregua, y parece llevarnos inexorablemente a un mundo en el que, tal como sugiere el final — ciertamente perturbador-, la supervivencia de uno implica necesariamente la anulación del otro.

A lo largo de este ensayo se han presentado poéticas que dan mayor o menor centralidad al texto dramático como eje del hecho teatral. Es importante señalar, sin embargo, que en ninguna de las obras analizadas, la palabra, en sí misma, carece de sentido y funcionalidad en escena, inclusive en el caso de Cercano Oriente, donde el texto no ha sido escrito ni antes ni después de la producción escénica. En el otro extremo de esta breve serie seleccionada, Por un reino, a través de una estética visual expresionista recreada por el lector y percibida por el espectador, es un teatro fuertemente anclado en la textualidad dramática previa. En este sentido, Cámara Gesell estaría en un punto intermedio entre uno y otro, ya que la puesta en escena reproduce fielmente el texto dramático de Veronese, pero al mismo tiempo introduce un elemento fundamental, ausente en la lectura de la obra: la actuación de las muñecas, que redimensiona el texto dramático. Por otra parte, una obra como la de Zangaro, fuertemente ligada a una preocupación social y política representa una tendencia que no es predominante en el nuevo teatro argentino. Se diría, más bien, que estamos ante un período en que muchos optan por una disociación del contexto inmediato en el que se ha producido la obra, y un acercamiento a temas más relacionados con el lugar y las vicisitudes del individuo en el marco del cambio de siglo.

Para concluir, este muestreo del teatro en Buenos Aires en los últimos años ha tenido un doble propósito. Por un lado, se ha querido poner de manifiesto la diversidad de la producción teatral de este período; por otro, demostrar que si bien es innegable que, efectivamente, en los noventa, con el surgimiento de muchos nuevos dramaturgos, se produce una creciente vuelta al texto en el hecho teatral, también coexisten manifestaciones (excepcionales, por cierto) que, continuadoras de la experiencia de los ochenta, relativizan esta afirmación. La exploración, en fin, se ha hecho en torno a tres vértices - tres campos magnéticos—, entre los muchos que diseñan la gran figura poligonal que es la creación teatral en Buenos Aires desde el noventa hasta hoy. Se ha reflexionado, pues, sobre un objeto de estudio cuyos bordes temporales nos vienen, inevitablemente, pisando los talones. Resulta de ello una peculiar posición crítica que conjuga la contemporaneidad 
entre la producción y la recepción crítica de los productos culturales estudiados, y la falta de una visión retrospectiva panorámica. De ahí que las obras hayan sido leídas/presenciadas con el fervor de lo inmediatamente cercano. De ahí que en la evaluación de la totalidad (necesariamente parcial) uno esté habilitado para trazar líneas estrictamente punteadas.

\section{BiBLIOGRAFÍA}

Aisemberg, Alicia. “Tendencias de la escena emergente en Buenos Aires”. Conjunto 120 (La Habana, enero-marzo 2001): 11-8.

Bergero, Adriana. "Estrategias fatales e intrusos: Discurso posmoderno y memoria implosiva en la Argentina de la re-democratización”. Memoria colectiva y políticas de olvido: Argentina y Uruguay, (1970-1990). Adriana Bergero y Fernando Reati, comps. Rosario: Beatriz Viterbo, 1997.

Catalán, Alejandro. "Producción de sentido actoral”. Teatro XXI 7/12 (Buenos Aires, otoño 2001): 15-20.

Correa, Rubens. "Nuevo sistema de subsidios”. Teatro XXI 7/12 (Buenos Aires, otoño 2001): 21-2

De Marinis, Marco. Entender el teatro: Lineamientos de una nueva teatrología. [1988]. Cecilia Prenz, trad. Buenos Aires: Editorial Galerna, 1997.

"Repensar el texto dramático”. Conjunto 102 (La Habana, enero-junio 1996): 4-8.

Dubatti, Jorge. "El canon de la multiplicidad”. Teatro CELCIT 9/11-12 (Buenos Aires, 1999): 30-6.

“El nuevo teatro de Buenos Aires (1983-1992)”. Cuadernos Hispanoamericanos 517-9 (Madrid, julio-septiembre 1993): 445-62.

"La dramaturgia de Daniel Veronese: Títeres, objetos y poéticas de renovación escénica”. Poéticas argentinas del siglo XX. Jorge Dubatti, recopilador. Buenos Aires: Editorial de Belgrano, 1998, 397-409.

"El teatro frágil. Procesos de pauperización y de cambio en el teatro argentino actual”. Teatro CELCIT 8/9-10 (Buenos Aires, 1998): 3-8.

Gesell, Arnold. Infancy and Human Growth. [1928]. New York: The Macmillan Company, 1929.

Graham-Jones, Jean. Exorcising History: Argentine Theater under Dictatorship. Lewisburg: Bucknell University Press, 2000.

Grüner, Eduardo. "Las fronteras del (des)orden. Apuntes sobre el estado de la sociedad civil bajo el menemato”. El menemato. Radiografía de dos años de gobierno de Carlos Menem. Oscar Martínez. Buenos Aires: Ediciones Letra Buena, 1991. $87-$ 118.

Kobialka, Michal (ed. y trad.). A Journey Through Other Spaces: Essays and Manifestos, 1944-1990. Tadeusz Kantor. Berkeley/Los Angeles/London: University of California Press, 1993.

Pellettieri, Osvaldo. "Modernidad y posmodernidad en el teatro argentino actual”. El teatro y su crítica. Osvaldo Pellettieri, ed. Buenos Aires: Galerna, Facultad de Filosofía y Letras (UBA), 1998. 147-67. 
Souza, Wal. "Por um reino: por uma proposta de iluminação da montagem”. Por um reino de Patricia Zangaro: Texto, pesquisa e prática teatral. Marcos Alexandre y Sara Rojo, eds. Belo Horizonte: Facultade de Letras da UFMG, 2000. 29-32.

Szulik, Dalia. "Pobreza y discriminación social: los ‘villeros"”. La cultura en la Argentina de fin de siglo: Ensayos sobre la dimensión cultural. Mario Margulis y Marcelo Urresti, comps. Buenos Aires: Oficina de Publicaciones del CBC, Universidad de Buenos Aires: 1997. 193-8.

Trastoy, Beatriz. "Nuevos procedimientos narrativos en el teatro latinoamericano de los 80 y 90”. Teatro CELCIT 11/19-20 (Buenos Aires, 2001) s/pág. [versión online. http://www.celcit.org.ar/secciones/publicaciones].

y Perla Zayas de Lima. Los lenguajes no verbales en el teatro argentino. Buenos Aires: Oficina de Publicaciones del CBC, Universidad de Buenos Aires, 1997.

Veronese, Daniel. Cámara Gesell. Cuerpo de prueba: Textos teatrales. Buenos Aires: Centro Cultural Ricardo Rojas, Oficina de publicaciones del CBC, Universidad de Buenos Aires, 1997.

“El Periférico de Objetos”. ARGENTORES. Catálogo de Autores Diciembre 1999/ Enero 2000. http://www.autores.org.ar/Dveronese/periferico.html La deriva. Buenos Aires: Adriana Hidalgo, 2000.

Villegas, Juan. Para la interpretación del teatro como construcción visual. Irvine, California: Ediciones de Gestos, 2000.

Wolff, Egon. Los invasores. Santiago de Chile: Pehuén Editores, 1990.

Zangaro, Patricia. Teatro y margen. Buenos Aires: Amaranta, 1997.

“Rebeldías de la diferencia”. http://www.teatroxlaidentidad.net/html/ publicacion01_07.htm 